\title{
Test studies on the potential energy surface and rate constant for the $\mathrm{OH}+\mathrm{O}_{3}$ atmospheric reaction
}

\author{
A.J.C. Varandas *, L. Zhang \\ Departamento de Química, Universidade de Coimbra, P-3049 Coimbra, Portugal \\ Received 27 June 2000; in final form 9 October 2000
}

\begin{abstract}
We report a single-valued potential energy surface for $\mathrm{HO}_{4}\left({ }^{2} \mathrm{~A}\right)$ from the double many-body expansion method. All $n$-body $(n=2-4)$ energy terms are taken from published studies on the relevant fragments, with a five-body energy term of Gaussian form added to mimic the experimental activation energy for the $\mathrm{OH}(v=0)+\mathrm{O}_{3}$ reaction. A detailed dynamics study of this reaction is also reported using classical trajectories. Good agreement with existing experimental data is obtained. (C) 2000 Elsevier Science B.V. All rights reserved.
\end{abstract}

\section{Introduction}

The hydrogen-oxygen systems play a central role in the chemistry of Earth's atmosphere [1,2], combustion chemistry [3], and laser processes [4]. In particular, the reaction

$\mathrm{OH}+\mathrm{O}_{3} \rightarrow \mathrm{HO}_{2}+\mathrm{O}_{2}$

influences the steady-state concentration of many trace gases which are important in stratospheric chemistry (the enthalpy of reaction is $\left.\Delta H^{0}=-40.01 \mathrm{kcal} \mathrm{mol}^{-1}[5]\right)$. It is also part of the so-called $\mathrm{HO}_{x}$ catalytic cycle for destruction of ozone in the natural stratosphere [1]. Moreover, in combination with $\mathrm{HO}_{2}+\mathrm{O}_{3} \rightarrow \mathrm{OH}+2 \mathrm{O}_{2}$, they form a reaction sequence which acts as a catalytic cycle for removing odd oxygen. This cycle is particularly important at altitudes below $25 \mathrm{~km}$ since it does not require oxygen atoms as do similar

${ }^{*}$ Corresponding author. Fax: +351-39-827-703.

E-mail address: varandas@qtvsl.uc.pt (A.J.C. Varandas). catalytic cycles involving nitrogen oxides or chlorine species [6].

Although much studied experimentally [5,7-9], no single theoretical study of the reaction in Eq. (1) has been reported in the literature so far. Since it is an important prototype reaction, which may even have social implications, such lack of theoretical work can only be attributed to difficulties in calculating a reliable $\mathrm{HO}_{4}\left({ }^{2} \mathrm{~A}\right)$ potential energy surface by correlated ab initio methods. Although largely due to the number of electrons involved, such computational difficulties get compounded by the fact that it is a five-atom system spanning a nine-dimensional (9D) configuration space. In fact, although there has been an increasing number of studies on four-atom reactions [10], very few have been so far carried out on five-atom species using global potential energy surfaces that cover all possible reaction channels. To our knowledge, the only available studies refer to five-atom [11,12] and six-atom [11] hydrogenic systems $\left(\mathrm{H}_{n}\right)$, and hence benefit from the small number of electrons and high permutational symmetry of the molecular 
system. We emphasize the methodological difficulties due to the fact that there are 10 possible diatomic fragments but only $3 \times 5-6=9$ Decius independent local normal coordinates $[13,14]$. However, we avoid any expansion in terms of these coordinates and hence such a problem will be absent here.

A major goal of the present work is to report a global double many-body expansion (DMBE) potential energy surface for $\mathrm{HO}_{4}\left({ }^{2} \mathrm{~A}\right)$ using previously reported information on the relevant $n$-body fragment systems: $\mathrm{OH}[15,16], \mathrm{HO}_{2}$ [17], $\mathrm{O}_{3}$ [18], $\mathrm{HO}_{3}$ [19], and $\mathrm{O}_{4}$ [20]. The DMBE potential energy surface so-obtained when truncated at the four-body level (denoted DMBE-4B heretofore) will then be complemented with a simple five-body energy term of Gaussian form whose parameters are calibrated from available data on the $\mathrm{OH}(v=0)+\mathrm{O}_{3}$ experimental activation energy and the requirement that no spurious features arise on the complete DMBE form. This will then be employed for detailed dynamics studies of the title reaction over the range of temperatures $200 \leqslant T \leqslant$ $500 \mathrm{~K}$ using the classical trajectory method. This Letter is organized as follows. Section 2 provides a description of the $\mathrm{HO}_{4}\left({ }^{2} \mathrm{~A}\right)$ DMBE potential energy surface, while the trajectory calculations are described in Section 3. The dynamics results are presented and discussed in Section 4, while the conclusions are in Section 5.

\section{Potential energy surface}

The potential energy surface assumes the form

$$
V\left(\mathbf{R}^{N}\right)=\sum_{n=2}^{N} \sum_{\mathbf{R}^{n} \subset \mathbf{R}^{N}}\left[V_{\mathrm{EHF}}^{(n)}\left(\mathbf{R}^{n}\right)+V_{\mathrm{dc}}^{(n)}\left(\mathbf{R}^{n}\right)\right],
$$

which is the familiar DMBE [14,21-25] for singlevalued surfaces. Thus, $\mathbf{R}^{n}$ specifies any set of $n(n-1) / 2$ interatomic distances referring to $n$ atoms, which is a subset of $\mathbf{R}^{N} \equiv\left(R_{1}, R_{2}, \ldots\right.$, $R_{N(N-1) / 2}$ ), and the energies of the isolated atoms have been taken as the reference energy. For the labelling of the atoms and definition of the associated interatomic coordinates, see Fig. 1 which shows the predicted molecular structures for the saddle point of the reaction $\mathrm{OH}+\mathrm{O}_{3} \rightarrow$ $\mathrm{HO}_{2}+\mathrm{O}_{2}$, the absolute minimum of the $\mathrm{HO}_{4}\left({ }^{2} \mathrm{~A}\right)$ DMBE potential energy surface, and the $\mathrm{OH} \cdots \mathrm{O}_{3}$ van der Waals minimum (see later). Note that the potential energy is partitioned in Eq. (2) into an extended-Hartree-Fock (EHF) part and a dynamical correlation (dc) part. All $n$-body EHF terms up to four-body level have been taken from previous work $[15,17-20]$ on the relevant fragment species. Similarly, the dc and remaining long-range terms such as electrostatic energies have been included up to the largest possible $n$-body level by using information reported elsewhere [15,17-20] on such interactions. Of course, the use of Eq. (2) to represent the potential energy surface of interacting atoms of any spin state and angular momentum rests on the complete neglect of the spin-recoupling and orientational effects which are inherent to the $\mathrm{HO}_{4}\left({ }^{2} \mathrm{~A}\right)$ system [25]. Such effects are introduced in an approximate way through appropriate calibration of the various $n$-body energy terms. Clearly, crossing seams are ignored and smoothed up.

Fig. 2 shows a perspective view of the $\mathrm{HO}_{4}$ DMBE-4B potential energy surface for the regions of configurational space with relevance to the studied reaction. To understand its meaning, let us define the following polar angles: $(\theta, \gamma)$ to specify the orientation of the $\mathrm{O}_{\mathrm{c}} \mathrm{O}_{\mathrm{d}}$ bond, and $(\beta, \phi)$ to specify that of $\mathrm{O}_{\mathrm{d}} \mathrm{H}$. Thus, $x$ represents the bond distance between the middle and terminal atoms of the ozone molecule (say, $\mathrm{O}_{\mathrm{b}} \mathrm{O}_{\mathrm{c}}$ ), while the $y$-axis denotes the distance between the oxygen atom in $\mathrm{O}_{\mathrm{d}} \mathrm{H}$ and the terminal oxygen atom of ozone $\left(\mathrm{O}_{\mathrm{c}}\right)$; to avoid confusion with chemical formulae, we use letters $(\mathrm{a}, \mathrm{b}, \mathrm{c}, \mathrm{d})$ in the text to label the oxygen atoms $(1,2,3,4)$. During the attack, the opening angle of the ozone molecule $\mathrm{O}_{a} \mathrm{O}_{b} \mathrm{O}_{c}$ has been kept fixed at its equilibrium value of $116.8^{\circ}$, while all the above polar angles were fixed at their values corresponding to the geometry of the $\mathrm{HO}_{4}$ minimum, namely $\theta_{\mathrm{m}}=34.032^{\circ}, \gamma_{\mathrm{m}}=49.810^{\circ}, \beta_{\mathrm{m}}=$ $179.808^{\circ}, \phi_{\mathrm{m}}=46.890^{\circ}$. The major features from this plot are seen to be the occurrence of a potential barrier in the entrance channel, and the fact that the reaction has a classical exoergicity of $42.2 \mathrm{kcal} \mathrm{mol}^{-1}$. Clearly, the barrier height $(\sim 12.5$ $\mathrm{kcal} \mathrm{mol}^{-1}$ ) looks appreciably higher in this plot 

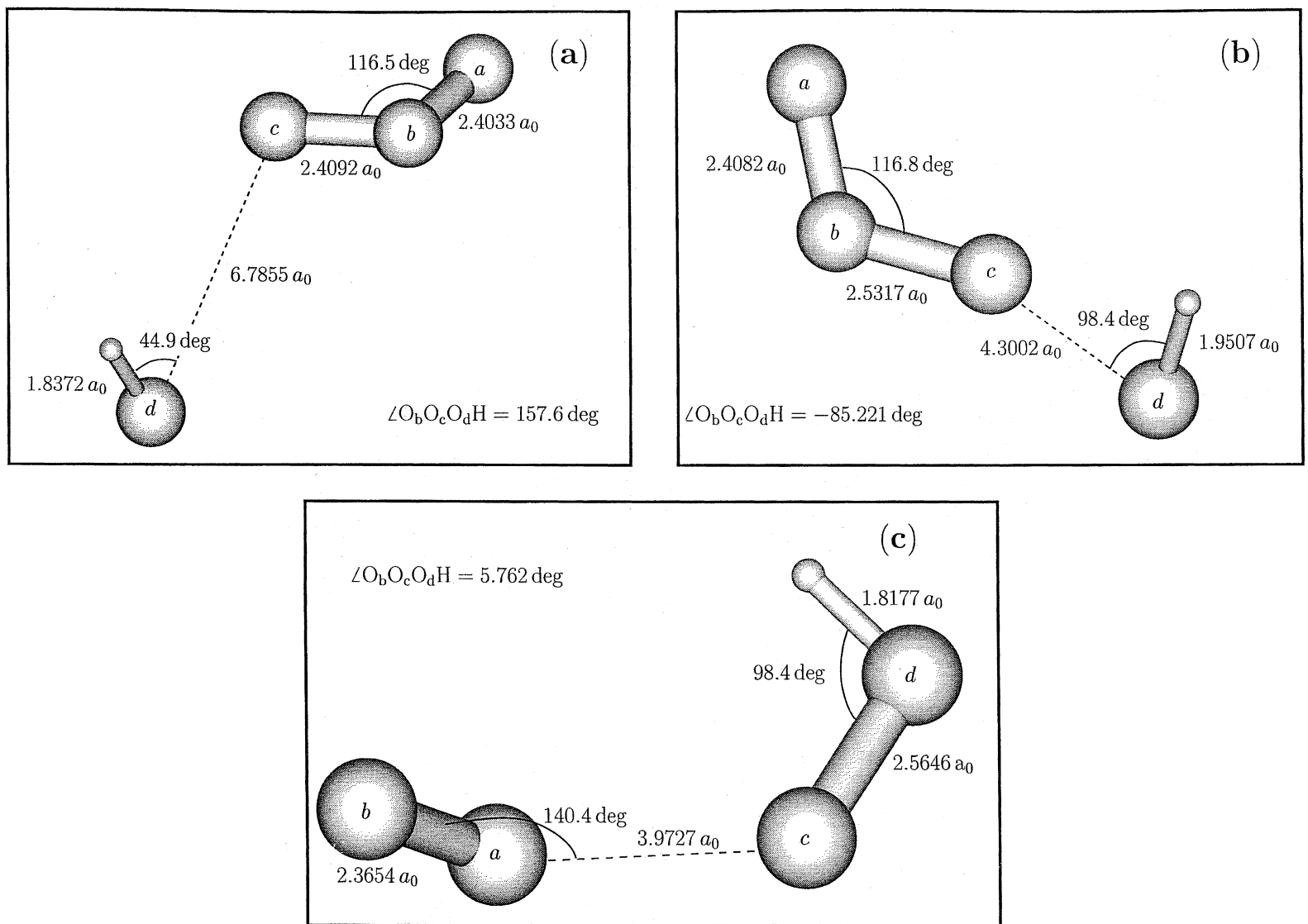

Fig. 1. Important structures for $\mathrm{HO}_{4}\left({ }^{2} \mathrm{~A}\right)$, and definition of atoms labelling: (a) predicted $\mathrm{OH} \cdots \mathrm{O}_{3}$ van der Waals structure; (b) saddle point for reaction $\mathrm{OH}+\mathrm{O}_{3} \rightarrow \mathrm{HO}_{2}+\mathrm{O}_{2}$; (c) predicted absolute minimum.

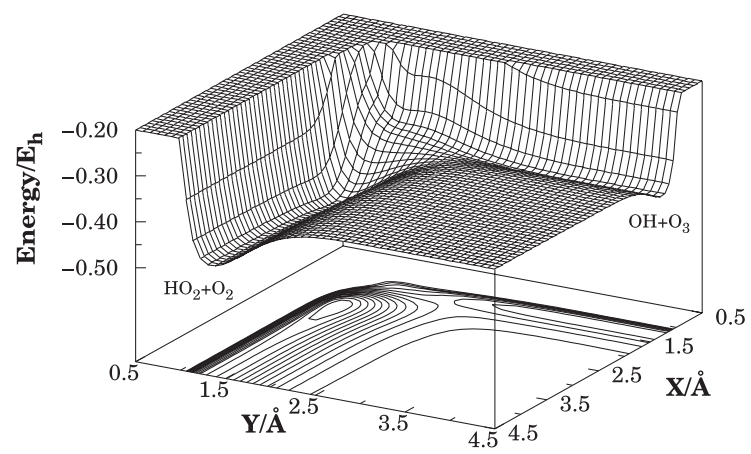

Fig. 2. A perspective/contour plot of the DMBE-4B potential energy surface for the reaction $\mathrm{OH}+\mathrm{O}_{3} \rightarrow \mathrm{HO}_{2}+\mathrm{O}_{2}$. Contours start at $-0.4733 E_{\mathrm{h}}$, and are equally spaced by $0.01 E_{\mathrm{h}}$.

than it is in reality, which is due to lack of proper relaxation of the remaining degrees of freedom. Indeed, the localization of such a barrier is a problem far from trivial, which has been solved numerically using cartesian coordinates. The calculated geometry, energy (relative to the $\mathrm{OH}+\mathrm{O}_{3}$ reactants asymptote), and harmonic normal mode frequencies are reported in Table 1. Although the classical barrier height $\left(V_{\mathrm{b}}=3.82 \mathrm{kcal} \mathrm{mol}^{-1}\right)$ calculated from the DMBE-4B potential energy surface is only about $2 \mathrm{kcal} \mathrm{mol}^{-1}$ higher than the recommended [5] experimental activation energy $\left[E_{\mathrm{a}}(\exp ) \sim 2 \mathrm{kcal} \mathrm{mol}^{-1}\right]$, such a difference clearly calls for the inclusion of five-body energy terms into the DMBE development if accurate results are to be expected. Thus, we have added the term $V_{\mathrm{EHF}}^{(5)}(\mathbf{R})=A \sum_{I=\dagger, \ddagger}\left\{\exp \left[-b \sum_{i=1}^{10}\left(R_{i}-R_{i}^{I}\right)^{2}\right]\right\}$, 
Table 1

Attributes of the minima ${ }^{\mathrm{a}}$ in $\mathrm{HO}_{4}\left({ }^{2} \mathrm{~A}\right)$ potential energy surface, and saddle point for the $\mathrm{OH}+\mathrm{O}_{3}$ reaction

\begin{tabular}{|c|c|c|}
\hline Property & DMBE-4B ${ }^{b}$ & $\mathrm{DMBE}^{\mathrm{c}}$ \\
\hline \multicolumn{3}{|c|}{ Absolute (van der Waals) minima } \\
\hline$R_{12} / a_{0}$ & 2.3661 & $2.3654(2.4033)$ \\
\hline$R_{13} / a_{0}$ & 3.9726 & $3.9727(4.0933)$ \\
\hline$R_{14} / a_{0}$ & 5.8889 & $5.8928(8.9245)$ \\
\hline$R_{15} / a_{0}$ & 5.4598 & $5.4669(8.4894)$ \\
\hline$R_{23} / a_{0}$ & 5.9905 & $5.9874(2.4092)$ \\
\hline$R_{24} / a_{0}$ & 7.7066 & $7.7053(7.9410)$ \\
\hline$R_{25} / a_{0}$ & 6.9856 & $6.9872(7.2153)$ \\
\hline$R_{34} / a_{0}$ & 2.5635 & $2.5646(6.7855)$ \\
\hline$R_{35} / a_{0}$ & 3.3867 & $3.3888(5.6359)$ \\
\hline$R_{45} / a_{0}$ & 1.8173 & $1.8177(1.8372)$ \\
\hline$V / E_{h}$ & -0.493178 & $-0.494025(-0.405746)$ \\
\hline$\omega_{1} / \mathrm{cm}^{-1}$ & 112 & $112(36)$ \\
\hline$\omega_{2} / \mathrm{cm}^{-1}$ & 132 & $133(62)$ \\
\hline$\omega_{3} / \mathrm{cm}^{-1}$ & 295 & $293(78)$ \\
\hline$\omega_{4} / \mathrm{cm}^{-1}$ & 401 & $397(97)$ \\
\hline$\omega_{5} / \mathrm{cm}^{-1}$ & 531 & $531(292)$ \\
\hline$\omega_{6} / \mathrm{cm}^{-1}$ & 1011 & $1009(720)$ \\
\hline$\omega_{7} / \mathrm{cm}^{-1}$ & 1420 & $1422(1067)$ \\
\hline$\omega_{8} / \mathrm{cm}^{-1}$ & 1712 & $1710(1129)$ \\
\hline$\omega_{9} / \mathrm{cm}^{-1}$ & 3715 & $3715(3740)$ \\
\hline \multicolumn{3}{|l|}{$\begin{array}{l}\text { Saddle } \\
\text { point }\end{array}$} \\
\hline$R_{12} / a_{0}$ & 2.4105 & 2.4082 \\
\hline$R_{13} / a_{0}$ & 4.2147 & 4.2076 \\
\hline$R_{14} / a_{0}$ & 8.1466 & 8.1218 \\
\hline$R_{15} / a_{0}$ & 8.8241 & 8.1662 \\
\hline$R_{23} / a_{0}$ & 2.5286 & 2.5317 \\
\hline$R_{24} / a_{0}$ & 6.4865 & 6.4199 \\
\hline$R_{25} / a_{0}$ & 6.8000 & 6.9300 \\
\hline$R_{34} / a_{0}$ & 4.3712 & 4.3002 \\
\hline$R_{35} / a_{0}$ & 5.0192 & 4.9755 \\
\hline$R_{45} / a_{0}$ & 1.9416 & 1.9507 \\
\hline$V / E_{\mathrm{h}}$ & -0.397224 & -0.401623 \\
\hline$\omega_{1} / \mathrm{cm}^{-1}$ & $194 i$ & $172 i$ \\
\hline$\omega_{2} / \mathrm{cm}^{-1}$ & 96 & 99 \\
\hline$\omega_{3} / \mathrm{cm}^{-1}$ & 132 & 151 \\
\hline$\omega_{4} / \mathrm{cm}^{-1}$ & 323 & 318 \\
\hline$\omega_{5} / \mathrm{cm}^{-1}$ & 525 & 526 \\
\hline$\omega_{6} / \mathrm{cm}^{-1}$ & 823 & 828 \\
\hline$\omega_{7} / \mathrm{cm}^{-1}$ & 1006 & 1037 \\
\hline$\omega_{8} / \mathrm{cm}^{-1}$ & 1089 & 1093 \\
\hline$\omega_{9} / \mathrm{cm}^{-1}$ & 3248 & 3210 \\
\hline
\end{tabular}

a Attributes of $\mathrm{OH} \cdots \mathrm{O}_{3}$ van der Waals minimum are in brackets.

${ }^{\mathrm{b}}$ Expansion truncated at four-body level.

where $A$ and $b$ are disposable parameters, and $R_{i}^{I}$ $(I=\dagger, \ddagger)$ are the geometries of the two equivalent saddle points (one for each terminal atom of the ozone molecule). Specifically, we have chosen the Gaussian amplitude to be $A=-2.62 \mathrm{kcal} \mathrm{mol}^{-1}$ in order to reproduce approximately the experimental activation energy for the title reaction. Within the spirit of transition state theory, we have then assumed that the activation energy could be calculated by taking into consideration the zero-point energy of both the reactants $\left(E_{\mathrm{ZPE}}^{\mathrm{R}}=10.5 \mathrm{kcal} \mathrm{mol}^{-1}\right)$ and transition state $\left(E_{\mathrm{ZPE}}^{\dagger}=11.3 \mathrm{kcal} \mathrm{mol}^{-1}\right)$, i.e., $E_{\mathrm{a}}=V_{\mathrm{b}}+E_{\mathrm{ZPE}}^{\dagger}-E_{\mathrm{ZPE}}^{\mathrm{R}}$. This leads to a classical barrier height of $V_{\mathrm{b}}=1.056 \mathrm{kcal} \mathrm{mol}^{-1}$ for the complete DMBE potential energy surface. In turn, the range parameter $b=0.048 a_{0}^{-2}$ has been selected from the requirement that the final DMBE potential energy surface should be smooth and with no apparent spurious features. Although the barrier is visibly lower, a plot of the resulting surface looks similar to Fig. 2 for DMBE-4B and hence will not be shown for brevity; for the saddle point attributes, see Table 1.

The calculated minimum energy reaction path for the title reaction is shown in Fig. 3. The salient feature is the minimum in the $\mathrm{HO}_{2}+\mathrm{O}_{2}$ products valley. In fact, this corresponds to the absolute minimum of the DMBE potential energy surface and leads to the prediction of a $\mathrm{HO}_{4}$ species which is stable by about $15 \mathrm{kcal} \mathrm{mol}^{-1}$ relative to $\mathrm{O}_{2}+\mathrm{HO}_{2}$ if zero-point energies are ignored; see

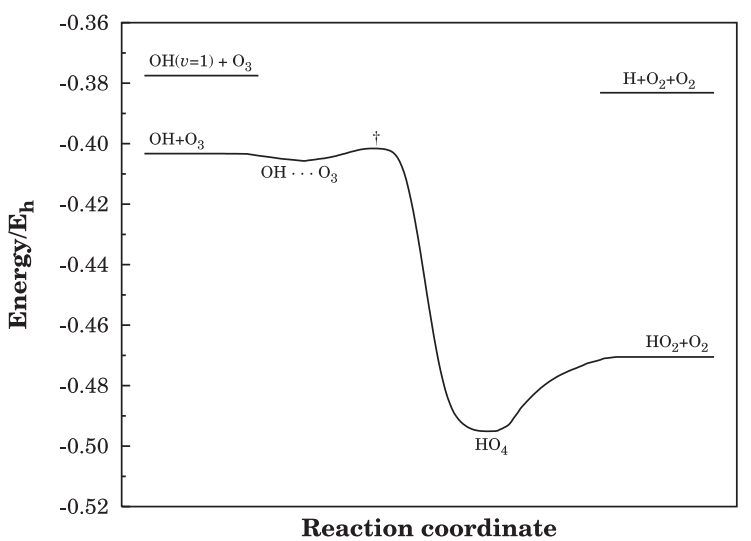

Fig. 3. Minimum energy path for formation of $\mathrm{HO}_{2}+\mathrm{O}_{2}$ and $\mathrm{O}_{2}+\mathrm{O}_{2}+\mathrm{H}$. The saddle point geometry is indicated by the symbol $\uparrow$. Also shown are the energy of $\mathrm{OH}(v=1)+\mathrm{O}_{3}$ and $\mathrm{H}+\mathrm{O}_{2}+\mathrm{O}_{2}$. 
Table 1 for its geometrical attributes and normal mode frequencies. Such a minimum is also apparent in the products valley of the plot in Fig. 2. Although there is some experimental evidence for the existence of a $\mathrm{HO}_{3}$ species [26,27] (the associated minimum also appears [19] in the products valley of the reaction $\mathrm{H}+\mathrm{O}_{3} \rightarrow \mathrm{OH}+\mathrm{O}_{2}$ ), no such claim has so far been made for $\mathrm{HO}_{4}$. However, if one thinks of the minimum in $\mathrm{HO}_{3}$ as partly due to the dominant electrostatic interaction between the $\mathrm{OH}$ dipole and the $\mathrm{O}_{2}$ quadrupole, then there are good grounds to believe that such an interaction may be even stronger in the case of $\mathrm{HO}_{4}$ since the dipole moment of $\mathrm{HO}_{2}$ is even larger than that of $\mathrm{OH}$. Of course this analysis may be too simplistic, and hence accurate $a b$ initio calculations would be valuable to assess the prediction of the stable $\mathrm{HO}_{4}\left({ }^{2} \mathrm{~A}\right)$ species made in the present work. Also visible from Fig. 2 is a small $\mathrm{OH} \cdots \mathrm{O}_{3}$ van der Waals minimum with a well depth of about $1.53 \mathrm{kcal} \mathrm{mol}^{-1}$; for attributes, see Table 1. In addition, Fig. 3 shows the energetics of the $\mathrm{OH}(v=1)+\mathrm{O}_{3}$ vibrational combination according to the $\mathrm{HO}_{4}$ DMBE potential energy surface. It is seen that the reaction channel leading to $\mathrm{O}_{2}+\mathrm{O}_{2}+\mathrm{H}$ is feasible even at low translational energies provided that the reactant $\mathrm{OH}$ molecule is vibrationally excited. However, for the case of $\mathrm{OH}(v=0)$ and the range of translational energies considered in the present work, such a reaction is energetically forbidden with the only feasible product channel being $\mathrm{HO}_{2}+\mathrm{O}_{2}$.

\section{Trajectory calculations}

The quasiclassical trajectory (QCT) method has been used to study the title reaction, with the trajectories being run using adapted versions of the MERCURY/VENUS96 [28] codes. Calculations have been carried for diatom-triatom translational energies in the range $1.2 \leqslant E_{\mathrm{tr}} / \mathrm{kcal} \mathrm{mol}^{-1} \leqslant 16$, as specified in Table 2 . In all cases the initial vibrational and rotational quantum numbers of the colliding $\mathrm{OH}$ molecule have been fixed at the ground level $(v=0, j=1)$. Similarly, the $\mathrm{O}_{3}$ molecule has been kept in its ground vibrational state $\left(v_{1}=0, v_{2}=0, v_{3}=0\right)$ while its rotational energy has been determined by using the microcanonical sampling scheme for a temperature of $300 \mathrm{~K} ; v_{1}$ is the quantum number for the symmetric stretching vibrational normal mode, $v_{2}$ the bending normal mode, and $v_{3}$ for the asymmetric stretching normal mode. The determination of the step size for numerical integration has been done by trial-and-error on the basis of accuracy requirements. A value of $1.5 \times 10^{-16} \mathrm{~s}$ has been found sufficient to warrant conservation of energy to better then two parts in $10^{5}$. In turn, the diatom-triatom initial separation has been fixed at $9 \AA$, a value sufficiently large to make the interaction negligible. The maximum value of the impact parameter $\left(b_{\max }\right)$ has been determined by following the usual procedure, with an estimated accuracy of \pm 0.1 A or so. A total of $3.8 \times 10^{4}$ trajectories has been run, which was enough to yield reactive cross-sections with an error smaller

Table 2

Summary of the trajectory calculations for the title reaction

\begin{tabular}{|c|c|c|c|c|c|}
\hline $\begin{array}{l}E_{\mathrm{tr}} \\
\left(\mathrm{kcal} \mathrm{mol}^{-1}\right)\end{array}$ & $b_{\max }$ & $\begin{array}{l}N_{\mathrm{r}} \\
(N)\end{array}$ & $100 P_{\mathrm{r}}$ & $\sigma^{\mathrm{r}} / a_{0}^{2}$ & $\Delta \sigma^{\mathrm{r}} / a_{0}^{2}$ \\
\hline 1.2 & 1.89 & $3(2000)$ & 0.15 & 0.0168 & 0.0097 \\
\hline 1.4 & 1.89 & $4(2000)$ & 0.20 & 0.0224 & 0.0112 \\
\hline 1.8 & 2.65 & $4(2000)$ & 0.20 & 0.0440 & 0.0220 \\
\hline 2.2 & 3.40 & $21(6000)$ & 0.35 & 0.1272 & 0.0277 \\
\hline 2.5 & 3.59 & $32(6000)$ & 0.53 & 0.2160 & 0.0381 \\
\hline 4.0 & 5.10 & $54(6000)$ & 0.90 & 0.7361 & 0.0997 \\
\hline 6.0 & 5.48 & $110(5000)$ & 2.20 & 2.0757 & 0.1957 \\
\hline 8.0 & 6.05 & $174(5000)$ & 3.48 & 3.9979 & 0.2978 \\
\hline 12.0 & 6.24 & $138(2000)$ & 6.90 & 8.4299 & 0.6924 \\
\hline 16.0 & 6.43 & $204(2000)$ & 10.20 & 13.2280 & 0.8777 \\
\hline
\end{tabular}


than about $20 \%(10 \%)$ for translational energies larger than $2.2 \mathrm{kcal} \mathrm{mol}^{-1}\left(4 \mathrm{kcal} \mathrm{mol}^{-1}\right)$; for convenience, the calculated values are reported in Table 2 with four decimal figures. Of course, such an accuracy is virtually impossible to get close to threshold, and we have used the overall quality of the fit to justify its reliability there.

For a specified translational energy $\left(E_{\mathrm{tr}}\right)$, the reactive cross-sections are given by $\sigma^{\mathrm{r}}=\pi b_{\max }^{2} P^{\mathrm{r}}$, and the associated $68 \%$ uncertainties are $\Delta \sigma^{\mathrm{r}}=$ $\left(\left(N-N^{\mathrm{r}}\right) / N N^{\mathrm{r}}\right)^{1 / 2} \sigma^{\mathrm{r}} ; N^{\mathrm{r}}$ is the number of reactive trajectories in a total of $N$, and $P^{\mathrm{r}}=N^{\mathrm{r}} / N$ is the reactive probability. From the reactive cross-section and assuming a Maxwell-Boltzmann distribution over $E_{\mathrm{tr}}$, the specific thermal rate coefficients are then obtained as

$$
\begin{aligned}
k(T)= & g_{\mathrm{e}}(T)\left(\frac{2}{k_{\mathrm{B}} T}\right)^{3 / 2}\left(\frac{1}{\pi \mu}\right)^{1 / 2} \\
& \times \int_{0}^{\infty} E_{\mathrm{tr}} \sigma^{\mathrm{r}} \exp \left(-\frac{E_{\mathrm{tr}}}{k_{\mathrm{B}} T}\right) \mathrm{d} E_{\mathrm{tr}},
\end{aligned}
$$

where $g_{\mathrm{e}}(T)=[1+\exp (-205 / T)]^{-1}$ accounts for the electronic degeneracies, $k_{\mathrm{B}}$ the Boltzmann constant, $\mu$ the reduced mass of the reactants, and $T$ is the temperature.

\section{Results and discussion}

Table 2 summarizes the trajectory calculations. For all initial translational energies considered in the present work (which are indicated in column one of Table 2), the only open reactive channels are:

$$
\begin{aligned}
\mathrm{O}_{\mathrm{d}} \mathrm{H}+\mathrm{O}_{\mathrm{a}} \mathrm{O}_{\mathrm{b}} \mathrm{O}_{\mathrm{c}} & \rightarrow \mathrm{HO}_{\mathrm{d}} \mathrm{O}_{\mathrm{a}}+\mathrm{O}_{\mathrm{b}} \mathrm{O}_{\mathrm{c}} \\
& \rightarrow \mathrm{HO}_{\mathrm{d}} \mathrm{O}_{\mathrm{c}}+\mathrm{O}_{\mathrm{a}} \mathrm{O}_{\mathrm{b}}
\end{aligned}
$$

where $\mathrm{a}, \mathrm{b}, \mathrm{c}$ and $\mathrm{d}$ label the four $\mathrm{O}$ atoms. In the case of indistinguishable atoms, the reactions in
Eqs. (5) and (6) have similar probabilities of occurrence. The channel

$$
\mathrm{O}_{\mathrm{d}} \mathrm{H}+\mathrm{O}_{\mathrm{a}} \mathrm{O}_{\mathrm{b}} \mathrm{O}_{\mathrm{c}} \rightarrow \mathrm{HO}_{\mathrm{d}} \mathrm{O}_{\mathrm{b}}+\mathrm{O}_{\mathrm{a}} \mathrm{O}_{\mathrm{c}}
$$

is essentially closed due to the high barrier encountered when attacking the central $\mathrm{O}$ atom of ozone. Thus, the probability for reaction (7) to take place is very small or zero.

Although not reported for brevity, interatomic distance vs time plots for a series of reactive trajectories yielding $\mathrm{HO}_{2}+\mathrm{O}_{2}$ have shown that they are short-lived. This might have been expected since the reaction occurs over a barrier and is highly exoergic. In fact, the average complex lifetime for the reactive trajectories at $E_{\mathrm{tr}}=$ $8 \mathrm{kcal} \mathrm{mol}^{-1}$ has been found to be $0.19 \mathrm{ps}$. To obtain this value we have used the following very simple procedure: first, we subtracted for every reactive trajectory the collision time of the reactive trajectory which had the smallest duration, and then attributed the excess time to the lifetime of the complex. Such a scheme should be realistic in the presence of direct collision dynamics as it happens to be the case in the present work. Note that the complex lifetimes estimated in the present work are enough only to allow a few oscillations in the vibrational modes of the complex, and hence can hardly warrant the possibility of internal energy exchange. We have also carried out an analysis of the scattering angle distribution for $E_{\mathrm{tr}}=$ $8 \mathrm{kcal} \mathrm{mol}^{-1}$. We have observed that the scattering tends to be forward, with the average scattering angle being approximately $68.4^{\circ}$. The corresponding product energy distribution is given in Table 3. Clearly, the product's internal energy is mostly channeled into vibration of the $\mathrm{HO}_{2}$ molecule. This suggests that the non-attacked $\mathrm{O}-\mathrm{O}$ bond of the ozone molecule acts essentially as a spectactor, remaining vibrationally cold after formation of the products.

Table 3

Percentages of energy partitioned to different degrees of freedom for the reaction $\mathrm{OH}(v=0)+\mathrm{O}_{3} \rightarrow \mathrm{HO}_{2}+\mathrm{O}_{2}$

\begin{tabular}{lllllll}
\hline \multirow{2}{*}{ Units } & & \multicolumn{2}{c}{$\mathrm{HO}_{2}$} & & \multicolumn{2}{c}{$\mathrm{O}_{2}$} \\
\cline { 2 - 4 } & $\left\langle E_{\mathrm{tr}}\right\rangle$ & $\left\langle E_{\mathrm{r}}\right\rangle$ & $\left\langle E_{\mathrm{v}}\right\rangle$ & & $\left\langle E_{\mathrm{r}}\right\rangle$ & $\left\langle E_{\mathrm{v}}\right\rangle$ \\
\hline $\mathrm{kcal} \mathrm{mol}^{-1}$ & 11.850 & 8.623 & 35.199 & 1.622 & 1.034 \\
$\%$ & 20.3 & 14.78 & 60.35 & 2.78 & 1.77 \\
\hline
\end{tabular}




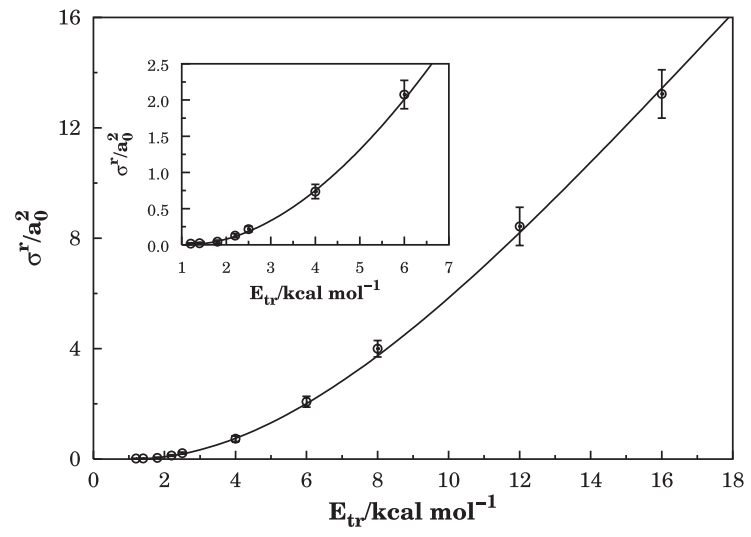

Fig. 4. Reactive cross-section $\sigma^{\mathrm{r}}$ as a function of the translational energy for $\mathrm{HO}_{2}+\mathrm{O}_{2}$ formation. Also shown for comparison are the measured $68 \%$ error bars and the fitted line given by Eq. (8).

We now examine the shape of the excitation functions (cross-section vs translational energy) which is shown in Fig. 4 together with the associated $68 \%$ error bars for formation of $\mathrm{HO}_{2}+\mathrm{O}_{2}$. One observes the common pattern found in reactions which have an energy threshold, i.e., $\sigma^{\mathrm{r}}$ is an increasing function of $E_{\mathrm{tr}}$. Such a threshold has been found to be close to $E_{\mathrm{tr}}^{\mathrm{th}} \sim 1.056 \mathrm{kcal} \mathrm{mol}^{-1}$, i.e., the classical barrier height of the DMBE potential energy surface. Indeed, a batch of one thousand trajectories run for $E_{\mathrm{tr}}=1.0 \mathrm{kcal} \mathrm{mol}^{-1}$ has shown no reactive trajectories at all. Its location has also been confirmed by plotting lowenergy trajectories over the $(x, y)$ plots in Fig. 3. To analytically describe $\sigma^{\mathrm{r}}\left(E_{\mathrm{tr}}\right)$, we have used the form

$\sigma^{\mathrm{r}}=C\left(E_{\mathrm{tr}}-E_{\mathrm{tr}}^{\mathrm{th}}\right)^{n} \exp \left[-m\left(E_{\mathrm{tr}}-E_{\mathrm{tr}}^{\mathrm{th}}\right)\right], \quad E \geqslant E_{\mathrm{tr}}^{\mathrm{th}}$

$\sigma^{\mathrm{r}}=0, \quad E<E_{\mathrm{tr}}^{\mathrm{th}}$

where $E_{\mathrm{tr}}^{\mathrm{th}}=1.056 \mathrm{kcal} \mathrm{mol}^{-1}$, and the remaining parameters have been determined from an eye-fit to the calculated cross-sections: $C=0.0925, n=$ 2.037, and $m=0.0355$ (units are such that with the energy in $\mathrm{kcal} \mathrm{mol}^{-1}$ the cross-section comes in $a_{0}^{2}$ ). Clearly, the line fits the data within the calculated error bounds.

The kinetics of the $\mathrm{OH}(v=0)+\mathrm{O}_{3}$ reaction has been much studied experimentally, and is now briefly surveyed. [8] measured its rate constant over the temperature range from 220 to $450 \mathrm{~K}$ using a discharge flow-resonance fluorescent technique, having obtained $k(T)=1.3 \times 10^{-12} \mathrm{exp}$ $(-1900 / R T) \mathrm{cm}^{3}$ molecule ${ }^{-1} \mathrm{~s}^{-1}$. Kurylo [7] used the flash photolysis-resonance fluorescence (FP/ $\mathrm{RF})$ technique to report $k(T=298 \mathrm{~K})=(6.5 \pm 1.0) \times$ $10^{-14} \mathrm{~cm}^{3}$ molecule ${ }^{-1} \mathrm{~s}^{-1}$. Ravishankara et al. [9] used a laser $\mathrm{FP} / \mathrm{RF}$ technique to get $k(T)=$ $1.82_{-0.29}^{+0.35} \times 10^{-12} \exp [(-930 \pm 50) / T] \mathrm{cm}^{3}$ molecule $^{-1} \mathrm{~s}^{-1}$. They also quoted [9] a result of Fischer and Davis [29]: $k(T)=(2.15 \pm 0.22) \times$ $10^{-12} \exp [(-969 \pm 40) / T] \mathrm{cm}^{3}$ molecule ${ }^{-1} \mathrm{~s}^{-1}$. Using a similar technique, Smith et al. [30] have more recently reported $k(T)=1.52 \times 10^{-12} \exp$ $[(-890 \pm 60) / T] \mathrm{cm}^{3}$ molecule ${ }^{-1} \mathrm{~s}^{-1}$ for $240 \leqslant T \leqslant$ $295 \mathrm{~K}$. In addition, the IUPAC Subcommittee on Gas Kinetic Data Evaluation for Atmospheric Chemistry indicated [5] as preferred values: $6.7 \times 10^{-14} \mathrm{~cm}^{3}$ molecule ${ }^{-1} \mathrm{~s}^{-1}$ for $T=298 \mathrm{~K}$, and $k(T)=1.9 \times 10^{-12} \exp (-1000 / T) \mathrm{cm}^{3}$ molecule ${ }^{-1} \mathrm{~s}^{-1}$ over the temperature range 220 $450 \mathrm{~K}$; the reliabilities are $\Delta \log k= \pm 0.15$ at $T=298 \mathrm{~K}$ and $\Delta(E / R)= \pm 300 \mathrm{~K}$. All such results are compared with ours in Fig. 5. These are obtained by substituting Eqs. (8) and (9) in Eq. (4) and performing the integration analytically, yielding

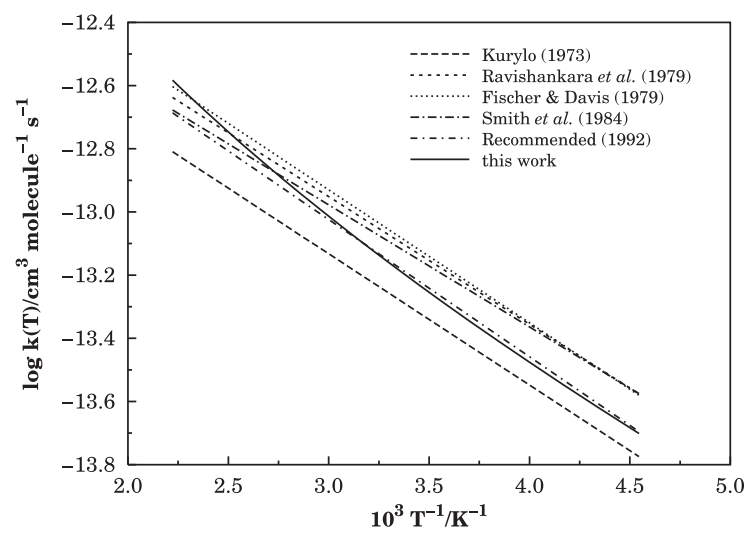

Fig. 5. Dependence on temperature of rate constant for the reaction $\mathrm{OH}(v=0)+\mathrm{O}_{3} \rightarrow \mathrm{HO}_{2}+\mathrm{O}_{2}$. Shown by the solid line is the result from Eq. (4), while the available experimental data [9], fitted Arrhenius plots [8,9,29,30], and curve [5] recommended by the IUPAC Subcommittee on Gas Kinetics Data Evaluation for Atmospheric Chemistry are also indicated. 


$$
\begin{aligned}
k(T)= & g_{\mathrm{e}}(T) C\left(\frac{8 R T}{\pi \mu}\right)^{1 / 2} \frac{(R T)^{n} \exp \left(-E_{\mathrm{tr}}^{\mathrm{th}} / R T\right)}{(1+m R T)^{n+2}} \\
& \times\left[\Gamma(n+2)+\Gamma(n+1)(1+m R T) E_{\mathrm{tr}}^{\mathrm{th}} / R T\right],
\end{aligned}
$$

where all symbols have their usual meaning. The agreement with the recommended data is seen from Fig. 5 to be good over the whole range of temperatures.

\section{Conclusions}

We have carried out a QCT study of the reaction $\mathrm{OH}(v=0)+\mathrm{O}_{3} \rightarrow \mathrm{HO}_{2}+\mathrm{O}_{2}$ using a newly developed DMBE potential energy surface for ground-state $\mathrm{HO}_{4}$. Although using an empirical calibration of a simple five-body energy term, the calculated $k(T)$ vs $T$ curve was shown to agree well with the recommended data over the whole range of temperatures, where the calculations and experimental data overlap. Thus, the current potential energy surface seems to be realistic at least for studying the kinetics of the title reaction. Such a result can provide also an indication on the convergence of the many-body expansion. Indeed, by considering the total energy, one gets for the $n$-body energy sum (up to $n=5$ ) at the $\mathrm{OH}+\mathrm{O}_{3}$ saddle point geometry the series $-0.55646+$ $0.14524+0.01400-0.00440$ (all numbers represent the total $n$-body energy in $E_{\mathrm{h}}$ ). Clearly, different results may presumably be obtained for other representations of the $n$-body energies if they become available, but one expects such changes to be not drastic. We therefore observe a good rate of convergence at the saddle point geometry, although we must take an uncommitted view for other geometries. Rather than implying that one may ignore high-order $n$-body energies, convergence of the many-body expansion may be taken [13] as an indication that it may generally suffice to choose simple $n$-body energy forms as in Eq. (3) to obtain a useful description of the full potential energy surface. Thus, the approach followed here may also be illuminating to study the reaction $\mathrm{HO}_{2}+\mathrm{O}_{3} \rightarrow \mathrm{OH}+2 \mathrm{O}_{2}$. Indeed, this exploratory work may call for further studies. First, one may use the current $\mathrm{HO}_{4}$ DMBE potential energy surface to investigate the kinetics of the title reaction for vibrationally excited states of $\mathrm{OH}$, where experimental data is available ([5], and references therein). Second, it would be interesting to investigate whether the weakly stable $\mathrm{HO}_{4}$ species predicted from the current work has further theoretical support. For this purpose, a characterization of the $\mathrm{HO}_{4}\left({ }^{2} \mathrm{~A}\right)$ potential energy surface using correlated $a b$ initio methods will be most valuable, and is currently under investigation in our group.

\section{Acknowledgements}

The support of Fundação para a Ciência e Tecnologia, Portugal under programme PRAXIS $\mathrm{XXI}$ is gratefully acknowledged.

\section{References}

[1] D.R. Bates, M. Nicolet, J. Geophys. Res. 55 (1950) 301.

[2] J.C. McDade, E. Llewellyn, J. Geophys. Res. 92 (1987) 7643.

[3] J.I. Steinfeld, J.S. Francisco, W.L. Hase, Chemical Kinetics and Dynamics, Prentice Hall, Englewood Cliffs, NJ, 1989.

[4] G.D. Downey, D.W. Robinson, J. Smith, J. Phys. Chem. 66 (1977) 1685.

[5] R. Atkinson, D.L. Baulch, R.A. Cox, R.F. Hampson Jr., J.A. Kerr, J. Troe, J. Phys. Chem. Ref. Data 21 (1992) 1125 .

[6] M.S. Zahniser, C.J. Howard, J. Chem. Phys. 73 (1980) 1620.

[7] M.J. Kurylo, Chem. Phys. Lett. 23 (1973) 467.

[8] J.G. Anderson, F. Kaufman, Chem. Phys. Lett. 19 (1973) 483.

[9] A.R. Ravishankara, P.H. Wine, A.O. Langford, J. Chem. Phys. 70 (1979) 984.

[10] A.J.C. Varandas, Int. Rev. Phys. Chem. 19 (2000) 199.

[11] A.J.C. Varandas, J.N. Murrell, Faraday Discuss. Chem. Soc. 62 (1977) 92.

[12] A. Aguado, C. Tablero, M. Paniagua, J. Chem. Phys. 110 (1999) 7789.

[13] J.N. Murrell, S. Carter, S.C. Farantos, P. Huxley, A.J.C. Varandas, Molecular Potential Energy Functions, Wiley, Chichester, 1984.

[14] A.J.C. Varandas, Adv. Chem. Phys. 74 (1988) 255.

[15] A.J.C. Varandas, J.D. Silva, J. Chem. Soc. Faraday Trans. 88 (1992) 941.

[16] A.J.C. Varandas, A.I. Voronin, Chem. Phys. 194 (1995) 91. 
[17] M.R. Pastrana, L.A.M. Quintales, J. Brandão, A.J.C. Varandas, J. Phys. Chem. 94 (1990) 8073.

[18] A.J.C. Varandas, A.A.C.C. Pais, Mol. Phys. 65 (1988) 843.

[19] A.J.C. Varandas, H.G. Yu, Mol. Phys. 91 (1997) 301.

[20] A.J.C. Varandas, A.A.C.C. Pais, S. Formosinho, I. Czismadia, L. Arnaut, Theoretical and Computational Models for Organic Chemistry, Kluwer Academic Publishers, Dordrecht, MA, 1991, p. 55.

[21] A.J.C. Varandas, J. Mol. Struct. Theochem. 120 (1985) 401.

[22] A.J.C. Varandas, M. Yáñez, Trends in Atomic and Molecular Physics, Universidad Autonoma de Madrid, Madrid, 1990, p. 113.

[23] A.J.C. Varandas, Chem. Phys. Lett. 194 (1992) 333.
[24] A.J.C. Varandas, A.I. Voronin, Mol. Phys. 95 (1995) 497

[25] A.J.C. Varandas, in: A. Laganá, A. Riganelli (Eds.), Lecture Notes in Chemistry, Springer, Berlin, in press.

[26] M. Speranza, Inorg. Chem. 35 (1996) 6140.

[27] M. Speranza, J. Phys. Chem. 102 (1998) 7535.

[28] W.L. Hase, MERCURY: a general Monte-Carlo classical trajectory computer program, QCPE\#453. QCPE Bull 16 (1996) 43 (An updated version of this code is VENUS96: W.L. Hase, R.J. Duchovic, X. Hu, A. Komornik, K.F. Lim, D.-H. Lu, G.H. Peslherbe, K.N. Swamy, S.R. van de Linde, A.J.C. Varandas, H. Wang, R. J. Wolf).

[29] S. Fischer, D.D. Davies, quoted in Ref [9].

[30] C.A. Smith, L.T. Molina, J.J. Lamb, M.J. Molina, Int. J. Chem. Kin. 16 (1984) 41. 